\title{
Estudo comparativo da madeira de Mimosa ophthalmocentra Mart. ex Benth e Mimosa tenuiflora (Willd.) Poir. (Fabaceae-Mimosoideae) na caatinga nordestina ${ }^{1}$
}

Lazaro Benedito da Silva ${ }^{2,5}$, Francisco de Assis Ribeiro dos Santos ${ }^{3}$, Peter Gasson ${ }^{4}$ e David Cutler ${ }^{4}$

Recebido em 27/08/2010. Aceito em 17/03/2011

\begin{abstract}
RESUMO
(Estudo comparativo da madeira de Mimosa ophthalmocentra Mart. ex Benth e Mimosa tenuiflora (Willd.) Poir. (FabaceaeMimosoideae) na caatinga nordestina). Pela importância econômica da madeira de algumas espécies do gênero Mimosa $\mathrm{L}$. ocorrentes na caatinga nordestina e pelo fato de Mimosa ophthalmocentra Mart. ex Benth. (jurema-de-imbira), às vezes, ser confundida com Mimosa tenuiflora (Willd.) Poir. (jurema-preta) ou vice-versa, este trabalho objetivou apresentar novos dados referentes à anatomia e densidade básica da madeira das duas espécies, visando oferecer subsídio para identificação das duas espécies, identificar caracteres anatômicos da madeira relacionando-os com o ambiente caatinga e apresentar o potencial energético que sua madeira possui. O estudo anatômico e a determinação da densidade da madeira foram realizados com amostras ao nível do peito (1,30 m acima do solo) e em dois galhos com diferentes diâmetros, de espécimes ocorrentes nos municípios de Serra Talhada e Sertânia, Pernambuco, Brasil. As espécies apresentam distinção expressa através do tipo de casca, coloração do cerne e do alburno, além das características peculiares da madeira. Mimosa ophthalmocentra apresenta camadas de crescimento distintas, constituídas por linhas de parênquima axial contendo cristais, parênquima axial escasso e menor quantidade de raios por $\mathrm{mm}^{2}$. Já Mimosa tenuiflora apresenta camadas de crescimento distintas, porém sem cristais, parênquima axial vasicêntrico, em faixas ou aliforme confluente, e maior percentagem de raios. Ambas apresentam algumas estruturas da madeira com as características anatômicas comuns às diversas espécies do gênero Mimosa, contribuindo assim para uma melhor caracterização do gênero. Pelos parâmetros anatômicos da madeira e pela elevada densidade básica $\left(>0,84 \mathrm{~g} / \mathrm{cm}^{3}\right)$, concluiu-se que as duas espécies apresentam perspectivas seguras para a produção de álcool combustível e carvão vegetal desde a fase de lenho juvenil. Mimosa ophthalmocentra apresenta maior potencial energético, pela maior percentagem de fibras e por possuir parênquima escasso e menor percentagem de raios.
\end{abstract}

Palavras-chave: Mimosa, anatomia e densidade de madeira, carvão, caatinga

\begin{abstract}
(Comparative study of Mimosa ophthalmocentra Mart. ex Benth and Mimosa tenuiflora (Willd.) Poir. (Fabaceae-Mimosoideae) wood in the caatinga of Northeast Brazil). Due to the economic importance of the wood of Mimosa L. species in Northeastern Brazil's caatinga and to the fact that Mimosa ophtalmocentra Mart. ex Benth. ("jurema-de-imbira") is confused with Mimosa tenuiflora (Willd.) Poir. ("jurema-preta") and vice versa, this research aimed to present new data related to the anatomy and basic density of the wood of both species; to contribute to the taxonomic study for differentiating them; to identify anatomical characters of the wood relating them to the caatinga environment; and to present the energetic potential that they possess. The anatomical study and wood density determination were carried out with samples at dbh level and with two branches of individuals within the municipalities of Serra Talhada and Sertânia (Pernambuco). The species both differed in bark type, color of heartwood and sapwood, besides the different anatomical characteristics found in the wood. Mimosa ophtalmocentra has distinct growth layers consisting of parenchyma lines containing crystals, scarce parenchyma and smaller quantity of rays. Mimosa tenuiflora, on the other hand, also has growth layers, but without crystals, axial parenchyma vasicentric, confluent and in bands, and greater percentage of rays. Both species have some wood elements with anatomical characteristics typical of representatives of Mimosa, contributing therefore to a better taxonomic understanding of the genus. Based on wood anatomical parameters and elevated basic density $\left(>0.84 \mathrm{~g} / \mathrm{cm}^{3}\right)$, the conclusion was reached that both species have great perspectives for the production of fuel alcohol and charcoal since juvenile wood age. Because Mimosa ophthalmocentra has scarce parenchyma and fewer rays, it shows greater energetic potential than Mimosa tenuiflora.
\end{abstract}

Key words: Mimosa, wood anatomy and density, charcoal, caatinga

\footnotetext{
1 Parte da tese de Doutorado do primeiro Autor

2 Universidade Federal da Bahia, Instituto de Biologia, Departamento de Botânica, Salvador, BA, Brasil

3 Universidade Estadual de Feira de Santana, Programa de Pós-Graduação em Botânica, Feira de Santana, BA, Brasil

4 Royal Botanical Gardens, Jodrell Laboratory, Kew

5 Autor para correspondência: lbsilva2003@yahoo.com.br
} 


\section{Introdução}

A anatomia da madeira, nos últimos anos, tem contribuído para a solução de questões taxonômicas, evolutivas e ecológicas. Barreta-Kuipers (1981) estudou a anatomia de madeira de algumas Fabaceae com relevância à taxonomia. Loureiro \& Silva (1968) apresentaram métodos para identificação macroscópica de madeiras, dados gerais sobre as espécies estudadas e respectivas descrições anatômicas. Fedalto et al. (1989) afirmaram que a anatomia da madeira, como pesquisa subsidiária, muitas vezes tem se prestado à solução de problemas taxonômicos e como fonte de dados complementares, sendo utilizada em trabalhos de inventários florestais, nos quais é comum deparar-se com material estéril ou incompleto. Atualmente, o interesse maior nesses estudos se deve, geralmente, ao auxílio na identificação e separação de espécies (Soffiatti \& Angyalossy-Alfonso 1999). Gasson et al. (2003) afirmaram que a anatomia da madeira representa uma importante ferramenta na identificação de amostras desconhecidas e uma fonte potencial de caracteres para o estudo em sistemática das Fabaceae.

Barreta-Kuipers (1981) apresentou um abrangente estudo sobre a anatomia da madeira de Fabaceae, no qual examinou 83 gêneros de Caesalpinioideae arbóreas, 35 de Mimosoideae e 68 de Papilionoideae, considerando caracteres relacionados ao tamanho e estratificação dos raios para discussão de semelhanças e diferenças dentro destas subfamílias. Gasson et al. (2003) descreveram os caracteres da madeira de 131 dos 158 gêneros de Caesalpinioideae, levando em consideração a organização dos dados no contexto filogenético.

A subfamília Mimosoideae apresenta cerca de 82 gêneros com aproximadamente 3.271 espécies, distribuídas nas regiões tropicais, subtropicais e temperadas-quentes do globo (Schrire et al. 2005). O gênero Mimosa L. apresenta cerca de 350 espécies endêmicas da América do Sul (Luckow 2005). Entre as espécies do gênero que ocorrem na caatinga pernambucana, estão Mimosa ophthalmocentra Mart. ex Benth. (jurema-de-imbira) e Mimosa tenuiflora (Willd.) Poir. (jurema-preta), simpátricas, pertencentes seção $B a$ tocaulon DC. e à série Leiocarpae Benth., que possui 28 espécies das quais nove ocorrem na caatinga do Nordeste (Barneby 1991). Lewis (2006) referiu 104 táxons de Mimosa para o Nordeste. Queiroz (2009) no trabalho "Leguminosas da Caatinga" cita 23 gêneros e 99 espécies de Mimosoideae para a caatinga.

Mimosa ophthalmocentra e M. tenuiflora são espécies de elevado potencial madeireiro para o nordeste (Figueirôa et al. 2005). M. tenuiflora apresenta grande potencial como elemento fundamental dentro de um sistema agroflorestal em Serra Talhada (Sampaio et al. 1993). Esta espécie é oportunista e secundária, estabelecendo-se em áreas antropizadas, além de apresentar uma grande amplitude de tolerância aos diferentes parâmetros físico-químicos do solo (Camargo-Ricalde 2000).
O reconhecimento das espécies de Mimosa não é muito fácil, sendo necessário recorrer a caracteres visíveis apenas sob lupa (10x), como por exemplo, os tricomas. Tenta-se, quando possível, usar caracteres macroscópicos que, mesmo não diagnosticando esses táxons em toda a sua área de distribuição, possam auxiliar no reconhecimento das espécies no âmbito da caatinga. Estes caracteres podem servir para formar grupos taxonômicos de espécies, mas para separar espécies muito parecidas eles não são suficientes, sendo então a utilização de caracteres anatômicos da madeira um auxílio importante para este reconhecimento. Atualmente, vários trabalhos de sistemática e evolução estão associados a caracteres da anatomia da madeira, principalmente quando empregam a cladística, provendo marcantes avanços nas filogenias apontadas (Herendeen \& Miller 2000).

Além de contribuir para a taxonomia, análises da anatomia da madeira e das características físicas e químicas da madeira são fundamentais em um estudo de manejo que vise o conhecimento de espécies florestais a serem utilizadas para fins energéticos, especialmente para a produção de lenha, prática comum nas comunidades rurais do nordeste do Brasil. Segundo Paula et al. (2000), a descrição anatômica das madeiras é de fundamental importância para a determinação de seu possível aproveitamento. Esta afirmação está baseada no fato de que as dimensões, a frequência e o arranjo das estruturas celulares e tecidos têm grande influência sobre as propriedades físicas e mecânicas da madeira.

Zimmermann (1983), Baas et al. (1983), Baas \& Carlquist (1985), Carlquist \& Hoekman (1985) e Lindorf (1994), abordando as floras de regiões de clima árido, semi-árido e mediterrâneo, estabeleceram as tendências gerais de organização da estrutura anatômica da madeira de plantas que habitam ambientes xéricos.

Considerando-se a importância econômica da madeira das espécies do gênero Mimosa para as comunidades da caatinga nordestina e o fato de, em alguns momentos, $M$. ophthalmocentra ser confundida com $M$. tenuiflora ou viceversa, este trabalho objetivou: (i) apresentar novos dados referentes à anatomia e a densidade básica da madeira das duas espécies; (ii) contribuir para o estudo taxonômico auxiliando na diferenciação das mesmas a partir de caracteres anatômicos da madeira como camadas de crescimento, percentagem de vasos, fibras e parênquimas axial e radial; (iii) identificar caracteres anatômicos da madeira relacionados com o ambiente da caatinga; e (iv) estimar a potencialidade energética dessas espécies a partir das características anatômicas e da densidade da madeira.

\section{Material e métodos}

Foram selecionadas áreas de caatinga nas Estações Experimentais da Empresa Pernambucana de Pesquisa Agropecuária (IPA-PE), em Serra Talhada (Fazenda Saco - 3.200 ha) e em Sertânia (Fazenda Cachoeira - 630 ha), por estes locais apresentarem vasta ocorrência de Mimosa 
ophthalmocentra e Mimosa tenuiflora, se encontrarem a uma distância de $200 \mathrm{~km}$ e pelas semelhanças florísticas (Fig. 1, 4). Sertânia localiza-se na microrregião de Moxotó, a 316 $\mathrm{km}$ da capital (Recife) e trata-se de uma área extensa de caatinga pouco perturbada, com vegetação mais fechada na encosta, formada por árvores e arbustos maduros (PROBIO 2000). A área experimental foi de $38 \mathrm{ha}$, conhecida como Manga do Cerecé. Serra Talhada localiza-se na microrregião do Pajeú, a $418 \mathrm{~km}$ da capital (Recife) e trata-se de uma extensa área de caatinga semi-densa, madura, pouco perturbada, apresentando extrato arbóreo com algumas árvores de até $12 \mathrm{~m}$ de altura, e arbustos e ervas bastante desenvolvidos (PROBIO 2000). A área experimental foi de 150 ha, região denominada de Pimenteira, pertencente à Empresa Pernambucana de Pesquisa Agropecuária - IPA. Os dados climáticos e geológicos encontram-se na Tab. 1.

Mimosa ophthalmocentra, espécie endêmica da caatinga (Giulietti et al. 2002), é um arbusto medindo de 3 a $6 \mathrm{~m}$, de caule rugoso com espinhos retos, folhas bipinadas com dois a quatro pares de pinas e 15 a 22 pares de folíolos por pina, inflorescência em forma de espiga, flores brancas a creme e frutos secos do tipo legume (Fig. 1). É usada como forrageira e as suas folhas e legumes são consumidas por cabras, ovelhas e bovinos; a madeira é utilizada como lenha e estacas; a resina é comestível, saborosa e recomendada no combate à gripe. M. tenuiflora é um arbusto que varia de $4 \mathrm{a}$ $7 \mathrm{~m}$ de altura, de caule reto ou inclinado, com espinhos retos ou ligeiramente curvos, ramos verdes e folhas viscosas pela presença de glândulas minúsculas; as folhas são bipinadas, com cinco a sete pares de pinas e 18 a 36 pares de folíolos por pina; a inflorescência é em forma de espiga, com flores brancas a creme e frutos do tipo legume (Fig. 4), também consumidos por cabras, ovelhas e bovinos, alta capacidade de produção de lenha e estacas, e um carvão considerado de boa qualidade. A casca é utilizada como cicatrizante e antiinflamatório. Além disso, é uma planta melífera, sendo suas flores boas fornecedoras de pólen (Costa et al. 2002). Segundo Maia (2004), a madeira de M. tenuiflora é muito resistente e empregada como estacas em construções de casas e pontes, além de fornecer excelente lenha e carvão de alto valor energético.

Para o estudo anatômico da madeira, foram coletadas amostras do tronco a altura do peito ( $\mathrm{DAP}=1,30 \mathrm{~m}$ do solo) e de dois ramos, o mais grosso e o mais fino do primeiro esgalhamento, de três árvores em cada uma das áreas de estudo. Foram preparadas lâminas permanentes com seções transversal, longitudinal tangencial e radial da madeira, com espessura variando de 18-25 $\mu \mathrm{m}$, utilizando-se micrótomo de deslize Spencer. As seções foram clarificadas com hipoclorito de sódio (30\%) e coradas com azul de alcião e safranina alcoólica (50\%) 1:1, tratadas em série alcoólica de 50 a $100 \%$, a cada $10 \%$ e montadas em euparol (Johansen 1940). Nas seções transversais, em áreas de 1 a $1 \mathrm{~mm}$ contíguas, ininterruptas, no sentido medula-casca, foi traçado um transecto ao longo de um raio da madeira, na região de maior diâmetro, para análise morfométrica. Para a mensuração dos elementos celulares foi feito material macerado. Foram mensuradas altura e diâmetro dos elementos de vaso, fibras e raios e percentagem por área dessas estruturas, incluindo o parênquima axial, utilizando-se o programa de análise de imagem KS 300 da Carl Zeiss, no Jodrell Laboratory do RBG Kew, Inglaterra. Foram realizadas 25 análises para cada parâmetro por espécime. Para a comparação das médias e análises de correlação foram utilizados os testes $t$ de Student e o Spearman Rank Correlation, respectivamente. Para a descrição dos parâmetros anatômicos, foram aplicadas as normas da IAWA Committee (1989).

Exsicatas de cada planta foram preparadas e depositadas no Herbário da Empresa Pernambucana de Pesquisa Agropecuária (IPA-PE). As amostras de madeiras e lâminas histológicas permanentes foram depositadas na Xiloteca do Instituto de Biologia da UFBA (M. ophthalmocentra: $\mathrm{n}^{\circ}$ 16, 017, 018 e M. tenuiflora 019, 020, e 021) no Laboratório de Micromorfologia da Universidade Estadual de Feira de Santana e no Laboratório de Micromorfologia do Jodrell Laboratory, Royal Botanic Gargens, Kew.

$\mathrm{Na}$ análise ultraestrutural dos elementos de vaso em microscopia eletrônica de varredura (MEV), foram utilizadas amostras de madeira de $1 \mathrm{~cm} \times 1 \mathrm{~cm} \times 1 \mathrm{~cm}$, retiradas da região mediana entre o alburno e o cerne. Estas amostras foram montadas em porta-espécimes com fita adesiva de grafite, recobertas com ouro em sputter Balzers SCD 050, analisadas e elétronfotomicrografadas em microscópio eletrônico de varredura LEO 1430VP. As análises foram feitas no MEV do PPGBot da Universidade Estadual de Feira de Santana.

Amostras de regiões próximas da medula e próximas da casca, coletadas do tronco à altura do peito e de dois galhos foram utilizadas na determinação da densidade da madeira, pela razão entre a massa seca da madeira $\left(\right.$ seco a $105^{\circ} \mathrm{C}$ ) e o volume saturado, de acordo com o método descrito por Vital (1984). Para a comparação das médias e análises de correlação foram utilizados os mesmos testes anteriormente citados para testar a comparação entre as médias.

\section{Resultados}

A diferença de coloração da casca das duas espécies é evidente. M. ophthalmocentra (jurema-de-imbira) apresenta casca fina, praticamente lisa e de coloração cinzaamarronzada com lenticelas amareladas (Fig. 3). Já $M$. tenuiflora (jurema-preta) apresenta casca grossa e rugosa, com grandes lenticelas e sulcos longitudinais liberando facilmente partes do ritidoma, e sua coloração é escura, característica importante que provavelmente lhe conferiu o nome popular de jurema-preta (Fig. 6). Ambas as espécies apresentam distinção entre alburno e cerne. $\mathrm{O}$ alburno de $M$. ophthalmocentra é de coloração clara amarelada e o cerne é marron, enquanto $M$. tenuiflora apresenta alburno amareloavermelhado e cerne escuro, também avermelhado (Fig. 2, 
Tabela 1. Dados climáticos e geológicos referentes às regiões de Sertânia e Serra Talhada, Pernambuco, Brasil.

\begin{tabular}{lcc}
\hline \multirow{2}{*}{ Clima } & Sertânia & Serra Talhada \\
\cline { 2 - 3 } & Tropical semiárido quente & Tropical semi-árido quente \\
\hline Precipitação & $350-600 \mathrm{~mm}$ & $450-750 \mathrm{~mm}$ \\
Temperatura & $35^{\circ} \mathrm{C}$ & $37^{\circ} \mathrm{C}$ \\
& $08^{\circ} 04^{\prime} 25^{\prime \prime} \mathrm{S}$ & $07^{0} 53^{\prime} 57^{\prime \prime} \mathrm{S}$ \\
Latitude e longitude & $37^{\circ} 12^{\prime} 24^{\prime \prime} \mathrm{W}$ & $38^{0} 18^{\prime} 09^{\prime \prime} \mathrm{W}$ \\
Altitude & $611 \mathrm{msnm}$ & $500 \mathrm{msnm}$ \\
\multirow{2}{*}{ Solo } & Maciço de gnais superficial, marron claro, ácido e franco & Maciço de gnais superficial, marron claro, ácido e \\
& argiloso com cascalho & franco argiloso com cascalho \\
\hline
\end{tabular}

5). Segundo Silva \& Sales (2008) as espécies se diferenciam também pela nervura eucampdódroma em M. ophthalmocentra e hifodódroma em M. tenuiflora e pelo cálice que da primeira é tubular e com 4-costelas na última.

\section{Descrição anatômica da madeira}

Qualitativamente, o lenho de Mimosa ophthalmocentra e M. tenuiflora varia em relação ao agrupamento dos vasos e o tipo de parênquima axial (Fig. 7, 11,12). Ambas as espécies apresentam camadas de crescimento delimitadas por linhas de parênquima axial, sendo que na $M$. ophthalmocentra essa camada apresenta cristais (Fig. 8), o que não foi observado na M. tenuiflora (Fig. 11). Em ambas as espécies os vasos apresentam arranjo difuso: na $M$. ophthalmocentra ocorrem solitários ou múltiplos de 2-6 em disposição radial e, às vezes, formando agrupamentos de até oito vasos (Fig. 7), já na $M$. tenuiflora os vasos são predominantemente solitários ou múltiplos de dois, ou eventualmente de três e mais de três (Fig. 11). Nas duas espécies, os elementos de vaso apresentam placas de perfuração simples e pontoações intervasculares multisseriadas alternas guarnecidas (Fig. 9, $10,13,14)$. Nas duas espécies as fibras são libriformes, com paredes muito espessas, ocorrendo também fibras gelatinosas (Fig. 8, 12). O parênquima axial em M. ophthalmocentra é escasso (Fig. 7), enquanto em M. tenuiflora revelou-se como paratraqueal vasicêntrico, aliforme ou confluente (Fig. 7, 11). Os raios das duas espécies assemelham-se estruturalmente, apresentando estratificação irregular (Fig. 15, 18), homogeneidade, são bisseriados e compostos de células procumbentes (Fig. 15-20). Cristais prismáticos em células subdivididas do parênquima axial estão presentes no lenho das duas espécies (Fig. 16, 19).

A Tabela 2 apresenta os dados quantitativos das características anatômicas da madeira das duas espécies. $\mathrm{O}$ comprimento (216-) 269 um (-351) e o diâmetro (81-) 108 $\mu \mathrm{m}$ (-149) dos elementos de vaso e o comprimento (10-) $907 \mu \mathrm{m}$ (-986) e o diâmetro (12-) $13 \mu \mathrm{m}$ (-15) das fibras, são maiores em M. tenuiflora, assim como a altura (128-) 168 $\mu \mathrm{m}(-208)$ e a largura (16-) $23 \mu \mathrm{m}(-31)$ dos raios.

O lenho dos indivíduos ocorrentes em Sertânia apresenta maior percentagem de vasos. Já em relação às fibras, ao parênquima e aos raios, as espécies apresentam diferenças em relação aos locais de coleta. As fibras de $M$. ophthalmocentra, que chegam a mais de $50 \%$, não diferiram significativamente em ambas as áreas experimentais (Tab. 3). Já em M. tenuiflora, a percentagem das fibras é maior nos espécimes de Serra Talhada (Tab. 4). A percentagem de parênquima é maior nos espécimes de $M$. ophthamocentra e menor nos de M. tenuiflora em Serra Talhada (Tab. 3, 4), na qual a percentagem de raios também é menor nesta área (Tab. 4). A percentagem de raios nos espécimes de $M$. ophthalmocentra de Sertânia não difere significativamente daqueles de Serra Talhada.

Nas Tabelas 3 e 4 pode-se observar também a comparação entre as porcentagens de tipos celulares no lenho dos galhos dos espécimes de Serra Talhada e Sertânia. Utilizouse o teste estatístico $t$ de student. M. ophthalmocentra não apresentou diferenças significativas em relação à percentagem de vasos nos dois municípios. Porém, $M$. tenuiflora apresenta uma maior percentagem de vasos em Sertânia. Mimosa ophthalmocentra apresenta maior percentagem de fibras em Sertânia, enquanto M. tenuiflora apresenta percentagem maior em Serra Talhada. A percentagem de parênquima em M. ophthalmocentra foi menor em Sertânia ocorrendo o contrário em $M$. tenuiflora. A percentagem dos raios de ambas as espécies foi maior em Serra Talhada.

Quanto à análise dos vasos no tronco, em ambas as espécies não ocorreram correlações significativas em relação à distância da medula, tanto em Serra Talhada quanto em Sertânia (Tab. 5, 6). Em relação às fibras de M. ophthalmocentra, como não houve diferença significativa entre os dados dos dois municípios, agruparam-se os espécimes das duas áreas e aplicou-se o teste de Spearman Rank Correlation, que indicou correlação negativa significativa, ou seja, à medida que se afasta da medula a percentagem de vasos diminui em ambos os municípios (Tab. 5), o mesmo ocorrendo em M. tenuiflora (Tab. 6).

Não ocorreu correlação entre a distância da medula e a percentagem de parênquima axial, tanto em Serra Talhada quanto em Sertânia, nos espécimes de M. ophthalmocentra (Tab. 5). Porém, em M. tenuiflora, à medida que se afasta da medula há uma crescente percentagem de parênquima axial (Tab. 6). Em ambas as espécies, a percentagem de 

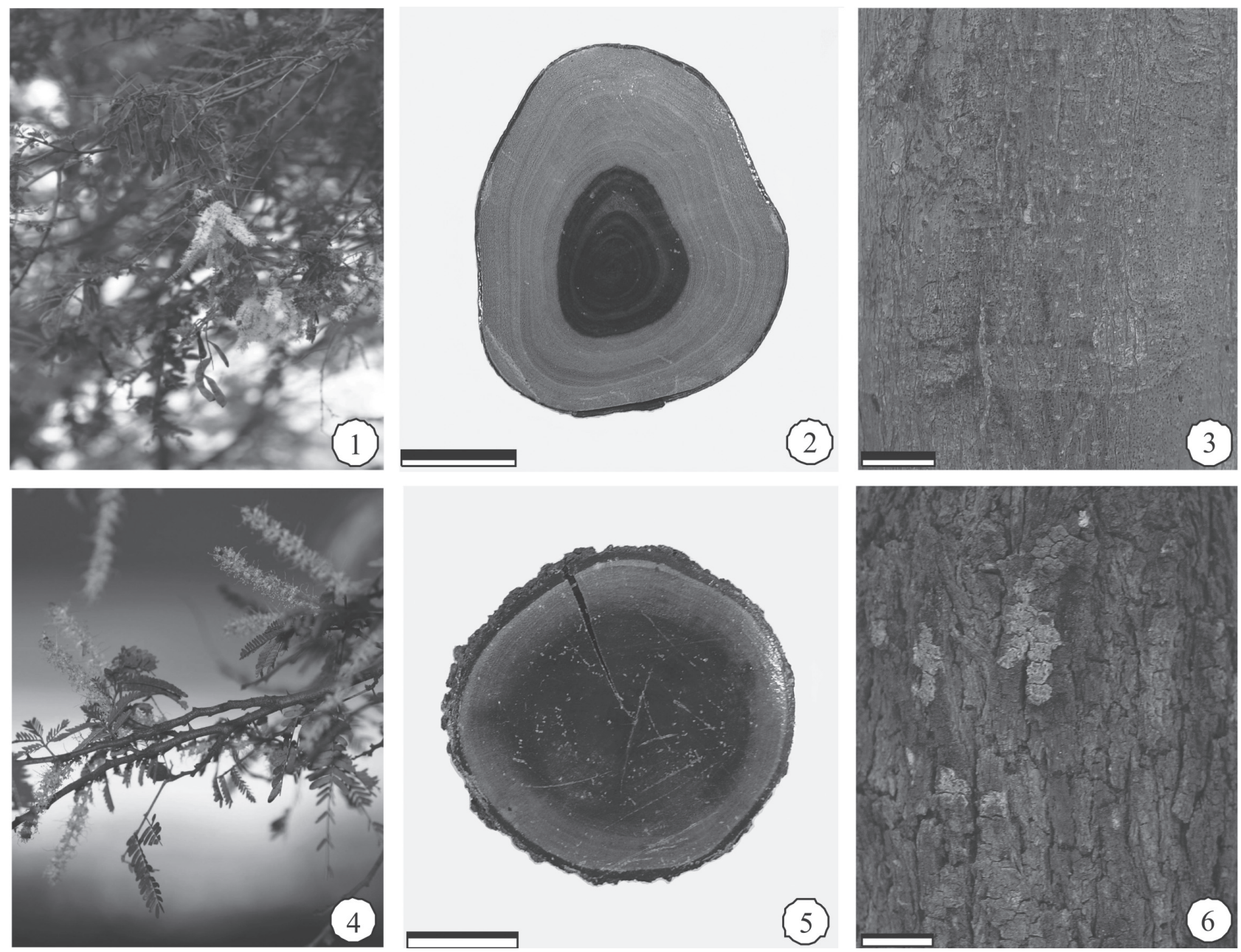

Figuras 1-3. Mimosa ophthalmocentra Mart ex Benth. 1. Ramos com inflorescências e frutos. 2. Seção transversal do tronco evidenciando alburno e cerne. 3. Casca. Figuras 4-6. Mimosa tenuiflora (Willd.) Poir. 4. Ramos com inflorescências. 5. Seção transversal do tronco evidenciando alburno e cerne. 6. Casca. Barras: Figuras $2,5=2 \mathrm{~cm}$; Figuras $3,6=1 \mathrm{~cm}$.

raios não apresentou correlação significativa em relação à distância da medula.

Para a análise da variação no sentido medula-casca nas seções transversais da madeira dos galhos, observou-se que a percentagem de vasos de Mimosa ophthalmocentra apresenta correlação significativa, tanto em Sertânia quanto em Serra Talhada, isto é, quanto mais longe da medula maior a percentagem de vasos (Tab. 5). Em M. tenuiflora não houve diferenças significativas em nenhum dos dois municípios (Tab. 6). Já a percentagem de fibras, em ambas as espécies, diminui à medida que a distância da medula aumenta.

Em relação à percentagem de parênquima axial e de raios de $M$. ophthalmocentra não houve correlações significativas em nenhum dos dois municípios (Tab. 5). A percentagem de parênquima de $M$. tenuiflora aumenta à medida que se distancia da medula, o mesmo ocorrendo em relação aos raios, apenas em Sertânia. Já em Serra Talhada, a percentagem de raios não apresenta diferença significativa em relação à distância da medula (Tab. 6).

\section{Densidade}

A densidade da madeira de tronco e galhos apresenta uma variação entre 0,82-1,06 g/ $\mathrm{cm}^{3}$ em M. ophthalmocentra e 0,86$1,03 \mathrm{~g} / \mathrm{cm}^{3} \mathrm{em}$ M. tenuiflora em Sertânia (Tab. 7). Em Serra Talhada a variação está entre $0,93-1,0 \mathrm{~g} / \mathrm{cm}^{3} \mathrm{em}$ M. ophthalmocentra e 0,88-1,0 g/ $/ \mathrm{cm}^{3} \mathrm{em}$ M. tenuiflora (Tab. 7). Não foram observadas diferenças significativas em relação à densidade da madeira mais próximo da medula e mais próximo da casca.

\section{Discussão}

\section{Comparação entre espécies de Mimosa}

A maioria dos caracteres anatômicos da madeira em $M$. ophthalmocentra e M. tenuiflora está de acordo com aqueles referidos para o gênero (Carnieletto \& Marchiori 1993; Marchiori 1993, 1996; Maccari \& Marchiori 1994; Paula 1995; 

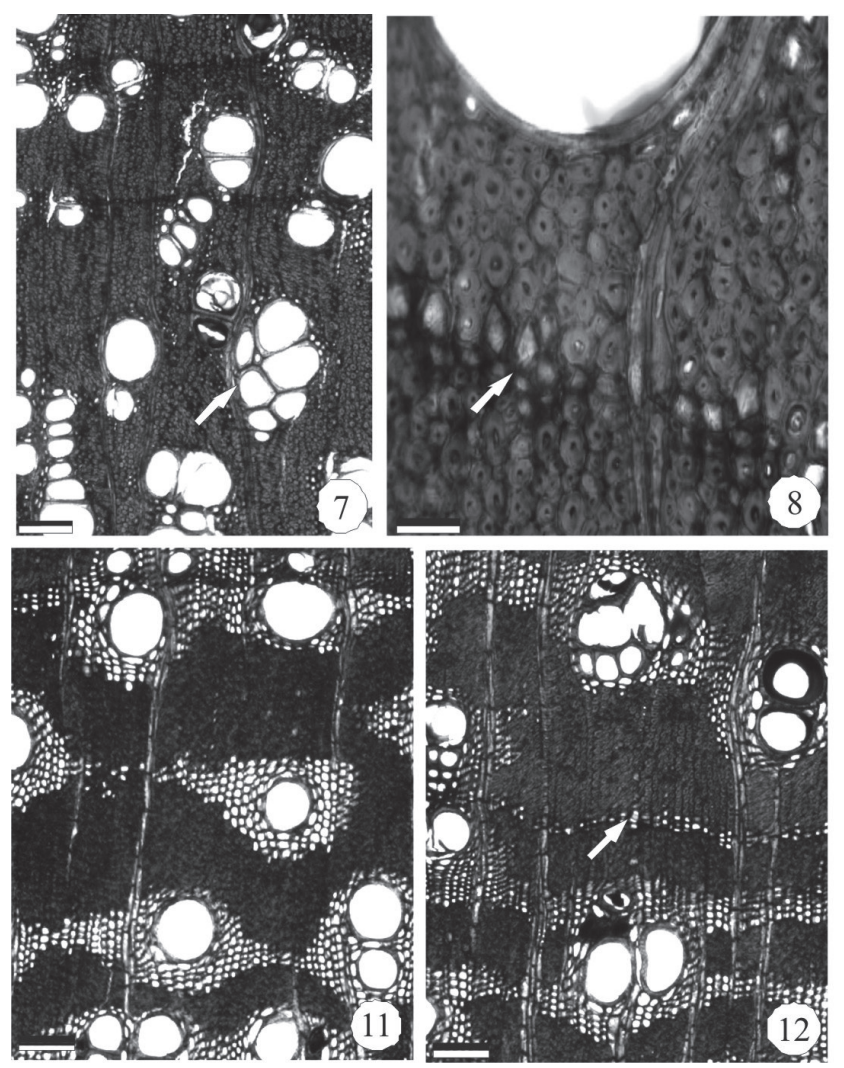

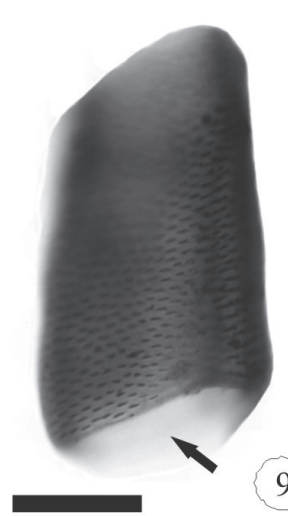

9

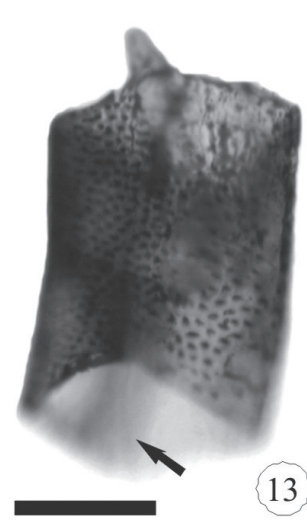

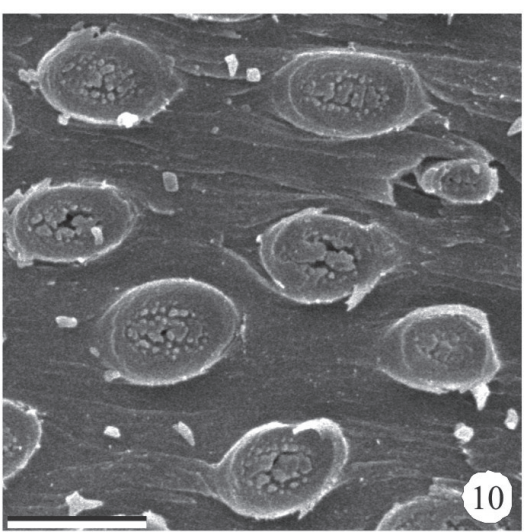

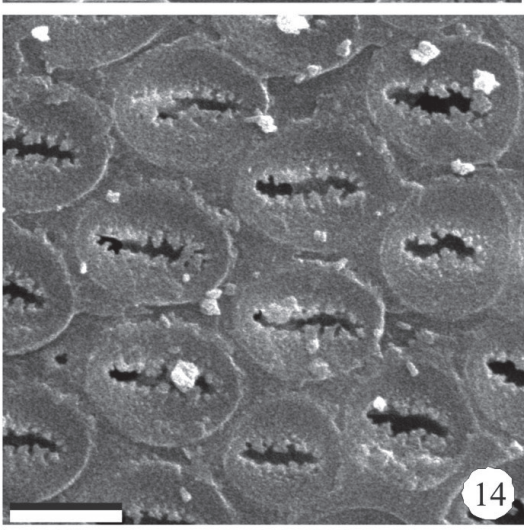

Figuras 7-10. Lenho de caule de Mimosa ophthalmocentra Mart ex Benth. 7-8. Seção transversal. 7. Parênquima axial escasso (seta), vasos solitários e múltiplos. 8. Parênquima axial marginal contendo cristais (seta), fibras de paredes espessadas. 9. Elemento de vaso com pontoações multisseriadas alternas e placas de perfuração simples (PS). 10. Parede do elemento de vaso em MEV evidenciando as pontoações. Figuras 11-14. Lenho de caule de Mimosa tenuiflora (Willd.) Poir. 11. Seção transversal. Parênquima axial aliforme formando confluência, vasos solitários e múltiplos de dois. 12. Parênquima marginal (seta branca), fibras de paredes espessadas. 13. Elemento de vaso com pontoações multisseriadas alternas e placa de perfuração simples (PS). 14. Parede do elemento de vaso em MEV evidenciando as pontoações. Barras: Figuras 7, 9, 11, $13=100 \mu \mathrm{m}$; Figura $8=10 \mu \mathrm{m}$; Figura 10, $14=5 \mu \mathrm{m}$; Figura $12=50 \mu \mathrm{m}$.

Marchiori \& Muniz 1996). Segundo Barneby (1991), essas duas espécies pertencem à seção Batocaulon DC. e à série Leiocarpae Benth. e a principal diferença morfológica entre elas é a presença de pontoações víscido-glandulares na face abaxial dos folíolos de $M$. tenuiflora. Neste estudo pode-se observar que existem diferenças marcantes também no lenho dessas duas espécies. M. ophthalmocentra apresenta parênquima axial escasso, camadas de crescimento distintas delimitadas por linha de parênquima marginal cujas células contém cristais, enquanto $M$. tenuiflora tem parênquima axial vasicêntrico, em faixas ou em confluência, e camadas de crescimento formadas também por parênquima em faixas, porém, sem cristais nessas células.

Marchiori (1993, 1996), Marchiori \& Muniz (1996) e Maccari \& Marchiori (1994) encontraram em , Mimosa eriocarpa Benth., Mimosa incana (Spreng.) Benth. e Mimosa pilulifera Benth. da seção Calothamnus Barneby, e em Mimosa sparsa Benth., da seção Mimosa L., camadas de crescimento formadas por parênquima marginal. No México, Camargo-Ricalde (2000) observou que M. tenuiflora, também apresenta camadas de crescimento distintas. As duas espécies analisadas neste estudo também apresentam este tipo de camada de crescimento.
Marchiori (1993), estudando Mimosa bimucronata (DC.) O. Kuntze, e Paula (1995), estudando Mimosa artemisiana Heringer \& Paula, ambas também da seção Batocaulon, observaram que essas espécies não possuem camadas de crescimento distintas. Assim, a presença de camadas de crescimento parece não ser um bom caráter para agrupar as espécies de Mimosa. Desta forma, faz-se necessária uma análise mais aprofundada em relação às camadas de crescimento nessas duas espécies e nas outras pertencentes às referidas seções para se obter conclusões mais consistentes.

Nas duas espécies analisadas neste estudo, a presença de cristais no parênquima que delimita as camadas de crescimento só foi observada em $M$. ophthalmocentra, podendo ser considerado um caráter diagnóstico na distinção entre ambas. Segundo Fahn (1990), a forma, a localização e o tipo de cristal são características úteis em estudos taxonômicos.

Especialistas do Oxford Forestry Institute, examinando o lenho de Acacia erioloba E. Mey. uma Mimosoideae da região sul da África, encontraram faixas estreitas distintas de células especializadas contendo cristais de oxalato de cálcio e observaram que essas faixas indicam a idade aproximada da respectiva árvore (Barnes 2004). Presença de cristais, também foi observada no lenho de outros in- 

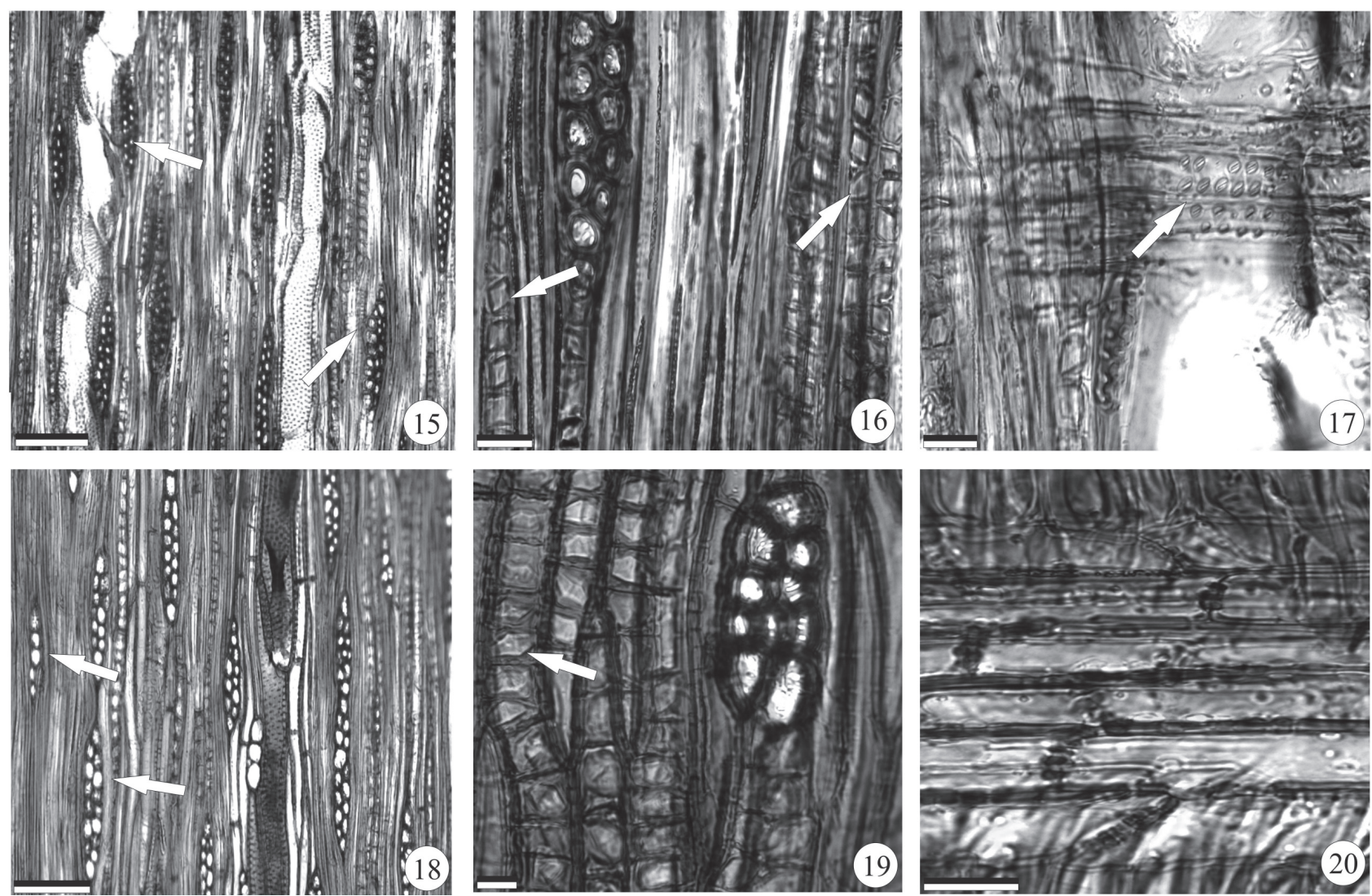

Figuras 15-17. Lenho de caule de Mimosa ophthalmocentra Mart ex Benth. 15-16. Seção tangencial. 17. Seção radial. 15. Raios bisseriados (setas), não estratificados 16. Cristais nas células do parênquima axial (setas). 17. Raio homogêneo de células procumbentes e pontoações radiovasculares (seta). Figuras 18-20. Lenho de caule de Mimosa tenuiflora (Willd.) Poir. 18-19. Seção tangencial. 20. Seção radial. 18. Raios uni e bisseriados (setas), não estratificados. 19. Cristais nas células do parênquima axial (seta). 20. Raio homogêneo composto de células procumbentes. Barras: Figuras 15, $18=100 \mu$ m; Figuras 16, $20=20 \mu \mathrm{m}$; Figura 17 = $10 \mu \mathrm{m}$; Figura $19=50 \mu \mathrm{m}$.

Tabela 2. Dados quantitativos $(\mu \mathrm{m})$ dos elementos anatômicos do lenho de Mimosa ophthalmocentra Mart. ex Benth e M. tenuiflora (Willd.) Poir. ocorrentes na caatinga em Pernambuco, Brasil. Valores expressos em (valor mínimo-) média (-valor máximo). $\mathrm{n}=6$ indivíduos por espécie.

\begin{tabular}{llcc}
\hline Variáveis & & Mimosa ophthalmocentra & Mimosa tenuiflora \\
\hline \multirow{3}{*}{ Elementos de vaso } & Comprimento & $(149-) 197(-243)$ & $(216-) 269(-351)$ \\
& Diâmetro & $(68-) 105(-203)$ & $(81-) 108(-149)$ \\
& Pontoações (f) & $(5-) 6(-7)$ & $(4-) 4(-6)$ \\
\hline \multirow{2}{*}{ Fibras } & Comprimento & $(702-) 843(-958)$ & $(10-) 907(-986)$ \\
& Diâmetro & $(9-) 11(-15)$ & $(12-) 13(-15)$ \\
\hline \multirow{2}{*}{ Raios } & Espessura da parede & $(5-) 4(-6)$ & $(-5) 5(-6)$ \\
& Altura & $(108-) 137(-156)$ & $(128-) 168(-208)$ \\
\hline
\end{tabular}

Tabela 3. Comparação da percentagem (\%) dos elementos do lenho no tronco e nos galhos de Mimosa ophthalmocentra (jurema-de-imbira) em Sertânia e Serra Talhada, Pernambuco, Brasil, utilizando-se o teste $t(\mathrm{P}<0,05) . \mathrm{n}=3$ indivíduos em cada local.

\begin{tabular}{|c|c|c|c|c|c|c|}
\hline & \multicolumn{3}{|c|}{ Tronco (DAP) } & \multicolumn{3}{|c|}{ Galhos } \\
\hline & Sertânia & & Serra Talhada & Sertânia & & Serra Talhada \\
\hline Vasos & 27,61 & $>$ & 23,08 & 26,98 & $=$ & 23,54 \\
\hline Fibras & 51,39 & $=$ & 50,74 & 51,19 & $>$ & 44,22 \\
\hline Parênquima & 12,10 & $<$ & 18,39 & 14,60 & $<$ & 23,48 \\
\hline Raios & 8,90 & $=$ & 7,79 & 7,23 & $<$ & 8,76 \\
\hline
\end{tabular}


Tabela 4. Comparação da percentagem (\%) dos elementos do lenho no tronco e nos galhos de Mimosa tenuiflora (jurema-preta) em Sertânia e Serra Talhada, Pernambuco, Brasil, utilizando-se o teste $t(\mathrm{P}<0,05)$. ( $\mathrm{DAP}=$ diâmetro a altura do peito $=1,30 \mathrm{~m}$ do solo). $\mathrm{n}=3$ indivíduos em cada local.

\begin{tabular}{lcccccc}
\hline & \multicolumn{3}{c}{ Tronco (DAP) } & \multicolumn{3}{c}{ Galho } \\
\cline { 2 - 7 } & Sertânia & & Serra Talhada & Sertânia & & Serra Talhada \\
\hline Vasos & 17,93 & $>$ & 12,08 & 19,04 & $>$ & 14,20 \\
Fibras & 30,81 & $<$ & 48,91 & 34,88 & $<$ & 43,88 \\
Parênquima & 30,85 & $>$ & 25,85 & 36,64 & $>$ & 30,93 \\
Raios & 20,42 & $>$ & 13,16 & 9,44 & $<$ & 10,98 \\
\hline
\end{tabular}

Tabela 5. Correlação entre a distância e a percentagem de elementos do lenho da medula para casca, no tronco e galhos de Mimosa ophthalmocentra (jurema-deimbira) em Sertânia e Serra Talhada, Pernambuco, Brasil, utilizando-se o teste Spearman Rank Correlation. (DAP = diâmetro a altura do peito = 1,30 $\mathrm{m}$ do solo; ns = não significante).

\begin{tabular}{|c|c|c|c|}
\hline & & Tronco (DAP) & Galhos \\
\hline \multirow{2}{*}{ Vasos } & Sertânia & ns & crescente \\
\hline & Serra Talhada & ns & crescente \\
\hline \multirow{2}{*}{ Fibras } & Sertânia & decrescente & decrescente \\
\hline & Serra Talhada & decrescente & decrescente \\
\hline \multirow{2}{*}{ Parênquima } & Sertânia & ns & ns \\
\hline & Serra Talhada & ns & ns \\
\hline \multirow{2}{*}{ Raios } & Sertânia & ns & ns \\
\hline & Serra Talhada & ns & ns \\
\hline
\end{tabular}

Tabela 6. Correlação entre a distância e a proporção de elementos do lenho da medula para casca, no tronco e galhos de Mimosa tenuiflora (jurema-preta) em Sertânia e Serra Talhada, Pernambuco, Brasil, utilizando-se o teste Spearman. (DAP = diâmetro a altura do peito = 1,30 $\mathrm{m}$ do solo; ns = não significante).

\begin{tabular}{|c|c|c|c|}
\hline & & Tronco (DAP) & Galhos \\
\hline \multirow{2}{*}{ Vasos } & Sertânia & ns & ns \\
\hline & Serra Talhada & ns & $\mathrm{ns}$ \\
\hline \multirow{2}{*}{ Fibras } & Sertânia & decrescente & decrescente \\
\hline & Serra Talhada & decrescente & decrescente \\
\hline \multirow{2}{*}{ Parênquima } & Sertânia & crescente & crescente \\
\hline & Serra Talhada & crescente & crescente \\
\hline \multirow{2}{*}{ Raios } & Sertânia & ns & crescente \\
\hline & Serra Talhada & ns & ns \\
\hline
\end{tabular}

Tabela 7. Variação da densidade básica do lenho no tronco e galhos de Mimosa ophthalmocentra (jurema-de-imbira) e Mimosa tenuiflora (jurema-preta) ocorrentes em Sertânia e Serra Talhada, Pernambuco, Brasil. (PM = próximo da medula; PC = próximo da casca).

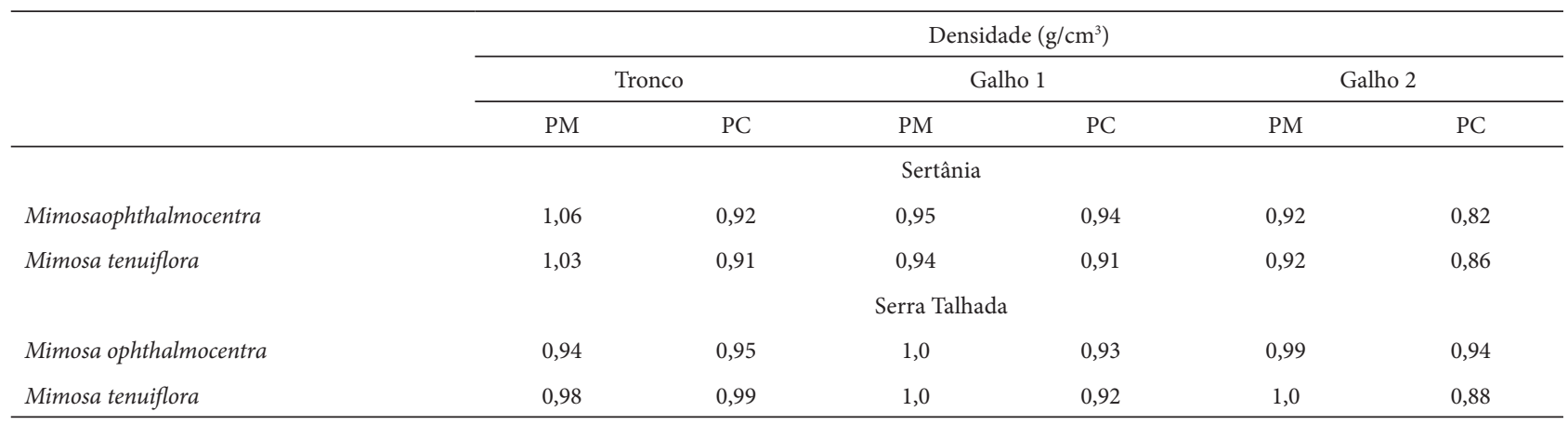


divíduos da família Fabaceae como Copaifera langsdorffii Desf. (Marcati et al. 2001), Pseudopiptadenia contorta (DC.) G. P. Lewis \& M. P. Lima (Ribeiro \& Barros 2006), Acacia melanoxylon R. Br. (Wilkins \& Papassotiriou 1989) e Enterolobium contortisiliquuon (Vell.) Morong (Lima et al. 2009). Neste último trabalho os autores relacionam a presença e/ou quantidade de cristais com o ambiente seco. M. ophthalmocentra e M. tenuiflora ocorrem na caatinga, ambiente xérico e apresentam cristas prismáticos em suas células do parênquima axial (Fig. 16, 19). A diferença é que, além da ocorrência no parênquima axial em geral, em $M$. ophthalmocentra ocorre faixas estreitas distintas de células especializadas contendo cristais.

Como Mimosa ophthalmocentra pertence à mesma subfamília de A. erioloba, que também apresenta camadas de crescimento delimitadas por células contendo cristais, pode-se supor que essas camadas possam revelar a idade aproximada de espécimes dessa espécie na caatinga. Todavia, Franceschi \& Horner-Jr. (1980) e Nakata (2003), estudiosos em formações cristalíferas em plantas informam que, em geral, cristais são formados a partir de íons proveniente do ambiente e da síntese metabólica de ácido no vegetal. Deste modo, a ocorrência pode depender da disponibilidade de determinado tipo de íon para o vegetal do meio externo. Deste modo, faz-se necessário um estudo sobre o comportamento do câmbio na formação das camadas de crescimento nessa espécie relacionando-o com os fatores ambientais tais como temperatura, pluviosidade, luminosidade e tipo de solo.

No período de seca na caatinga, ambas as espécies perdem parte de suas folhas, ficando praticamente apenas os troncos e os galhos, a camada de cristais observada em M. ophthalmocentra pode corroborar na distinção entre ambas contribuindo assim na separação taxonômica das mesmas.

Em Mimosa artemisiana, M. eriocarpa, $M$. incana, $M$. pilulifera e M. sparsa ocorrem poros com distribuição difusa (Carnieletto \& Marchiori 1993; Maccari \& Marchiori 1994; Paula 1995; Marchiori \& Muñiz 1996; Marchiori 1996). Marchiori (1993), analisando M. bimucronata, observou poros semidifusos. Camargo-Ricalde (2000) já tinha observado, em M. tenuiflora do México, poros de distribuição difusa, alguns solitários, porém a maioria múltipla de dois radial, vasos com pontoações intervasculares areoladas alternas e placa de perfuração simples, caracteres semelhantes aos das espécies estudadas provenientes da caatinga. Pode-se observar que vasos solitários e múltiplos e a distribuição difusa dos poros, presentes nas espécies estudadas, corroboram os dados de Alves \& Angyalossy-Alfonso (2000), os quais afirmaram ser essas características comuns na flora brasileira, diferente do que ocorre em regiões de clima temperado, nas quais outras distribuições como dendríticas e porosas são mais comuns.

As diferenças significativas encontradas entre os comprimentos e diâmetros dos elementos de vaso e fibras da ma- deira das duas espécies, deste estudo, podem ser utilizadas na distinção entre elas na caatinga (Tab. 2).

Camargo-Ricalde (2000), descrevendo a madeira de $M$. tenuiflora do México, encontrou elementos de vaso com diâmetro tangencial moderadamente pequeno, de (47)80(91) $\mu \mathrm{m}$, e extremamente curtos, de (113)160(220) $\mu \mathrm{m}$, fibras libriformes muito curtas, de (236)546(803) $\mu \mathrm{m}$, com diâmetro mediano de (9)14(22) $\mu \mathrm{m}$ e paredes espessas de (6)7(8) $\mu \mathrm{m}$, e raios com (69)144(315) de altura e (8)10(18) de largura, diferindo do encontrado nos espécimes da espécie analisados na caatinga (Tab. 2).

As diferenças anatômicas observadas em $M$. tenuiflora entre os espécimes de Sertânia e Serra Talhada (região de caatinga do Brasil) e de Oaxaca e Chiapas (região de clima semiseco e quente do México) estudadas por CamargoRicalde (2000) podem ser atribuídas às diferenças de precipitação pluviométrica anual, que é maior nesta região do México (500-1200mm) que nos municípios da caatinga (350-750mm) e à diferença de altitude de 760-1250 msnm e 500-611 msnm, respectivamente. A menor ocorrência de chuva pode induzir o câmbio à formação de elementos de vaso com comprimento e diâmetro maiores para aproveitar ao máximo a quantidade de água disponível no solo. Além disso, como os raios são formados por células parenquimáticas com função de reserva, quando são maiores e mais largos representam uma estratégia de sobrevivência em períodos mais secos, conforme observou Alves \& Angyalossy-Alfonso (2000), estes caracteres como uma das tendências ecológicas em madeiras de espécies brasileiras, especialmente de ambientes secos.

As fibras, tanto em Mimosa tenuiflora quanto em $M$. ophthalmocentra da caatinga apresentam comprimento maior que as de M. tenuiflora do México, porém o diâmetro e a espessura da parede foram semelhantes (Tab. 2).

Durante este estudo foi realizado um levantamento sobre trabalhos relativos ao lenho de espécies de Mimosa. Foram encontrados oito espécies analisadas M. artemisiana, M. bimucronata, $M$. eriocarpa, $M$. incana, M. pilulifera e M. sparsa (Marchiori 1993, 1996; Carnieletto \& Marchiori 1993; Maccari \& Marchiori 1994; Paula 1995; Marchiori \& Muniz 1996). Todas estas com parênquimas semelhantes ao encontrado para $M$. tenuiflora, dos tipos axial vasicêntrico aliforme e em confluência. Enquanto M. ophthalmocentra difere de todas estas do mesmo gênero, merecendo estudos mais aprofundados que poderão demonstrar um diferencial desta espécie.

Mimosa ophthalmocentra e M. tenuiflora apresentam raios homogêneos, similares aos de Mimosa artemisiana e M. bimucronata (Marchiori 1993; Paula 1995), pertencentes às mesmas seção e série. Ambas as espécies aqui analisadas seguem o padrão característico das Mimosoideae, de acordo com Barreta-Kuipers (1981). Segundo esta autora, a homogeneidade dos raios é uma das características mais notáveis no lenho desta subfamília, constituindo-se em importante tendência evolutiva do grupo, a partir das 
Fabaceae-Caealpinioideae. Porém, raios heterogêneos foram encontrados em $M$. daleoides Benth., $M$. eriocarpa, $M$. eriocarpa, M. pilulifea, M. sparsa (Carnieletto \& Marchiori 1993; Maccari \& Marchiori 1994; Marchiori 1982; Marchiori 1996; Marchiori \& Muniz 1996), todas pertencentes à outras seções. A autora não cita em seu trabalho nenhuma destas espécies, tampouco M. ophthalmocentra e M. tenuiflora. Estudos referentes às espécies citadas na literatura, que apresentam raios heterogêneos, devem ser analisados objetivando uma melhor caracterização da madeira do gênero Mimosa quanto aos raios.

Os raios de M. tenuiflora da caatinga de Pernambuco, Brasil, diferem da M. tenuiflora do México. CamargoRicalde (2000) encontrou nesta última, raios unisseriados e parcialmente bisseriados, heterogêneos, extremamente baixos de (69)144(315) $\mu \mathrm{m}$ e extremamente finos de (8)10(18) $\mu \mathrm{m}$, diferindo dos resultados encontrados em $M$. tenuiflora da caatinga (Tab. 2). Assim, a variação dos raios em relação à composição (homogêneos ou heterogêneos) e quanto ao número de células de largura parece ser um caráter variável no gênero. Pelas diferenças de $M$. tenuiflora do Brasil e do México, pode-se até inferir um caráter variável na própria espécie. Uma espécie vegetal pode apresentar plasticidade fenotípica em função dos fatores ambientais. A pluviosidade, luminosidade, temperatura e solo da caatinga são típicos de Bioma xérico. Estes podem influenciar nas características da madeira permitindo a plasticidade aqui discutida. Propõe-se, portanto, um estudo ecológico mais detalhado a esse respeito.

M. ophthalmocentra e M. tenuiflora apresentam raios extremamente baixos, semelhantes à Mimosa artemisiana, M. eriocarpa, $M$. incana, $M$. pilulifera, $M$. sparsa e M. bimucronata (Carnieletto \& Marchiori 1993; Marchiori 1993, 1996; Maccari \& Marchiori 1994; Paula 1995; Marchiori \& Muniz 1996), podendo representar uma característica predominante no gênero, mas são necessárias análises de uma quantidadde maior de espécies para se confirmar este fato.

\section{Comparação em relação ao ambiente}

A presença de elementos de vasos com pontoações guarnecidas é uma característica geral da maioria das $\mathrm{Fa}$ baceae (Carlquist 1983). De acordo com Herendeen (2000) e Gasson et al. (2003), apesar de algumas Caesalpinioideae não apresentarem elementos de vaso com esta característica, o gênero Caesalpinia e todos os gêneros de Mimosoideae e Papilionoideae apresentam este tipo de pontoação em seus elementos de vaso. Segundo estes autores, pontoações guarnecidas podem ter evoluído dentro das Fabaceae e, consequentemente, esta característica pode ser uma sinapomorfia para união da maioria dos gêneros e a segregação da tribo Cercideae e 15 gêneros da tribo Cassieae.

Geralmente os táxons que apresentam elementos de vaso com pontoações guarnecidas têm placas de perfuração simples. Esta correlação, juntamente com as tendências ecológicas, contrastando com as placas de perfuração escalariformes, tem inspirado a hipótese funcional de que as pontoações guarnecidas contribuem para a segurança hidráulica. Este tipo de pontuação parece facilitar a reversão do embolismo em regiões secas e quentes com altas taxas de transpiração (Jansen et al. 2003; Jansen et al. 2004). Portanto, além de ser um traço filogenético, as pontoações guarnecidas parecem representar uma estratégia adaptativa de sucesso à competição e sobrevivência. M. ophthalmocentra e M. tenuiflora aqui estudadas confirmam essas acepções, pois pertencem a família Mimosoideae e encontram-se em ambiente quente e seco.

As guarnições nas pontoações são importantes na prevenção de embolia, aumentando a aderência das moléculas de água à parede das células (Carlquist 1983, 1988). Assim, essas pontoações seriam adaptativas em plantas de ambientes que sofrem algum tipo de estresse hídrico, como é o caso de $M$. ophthalmocentra e $M$. tenuiflora na caatinga. Alves \& Angyalossy-Alfonso (2000), corroborando os estudos ecológicos em anatomia de madeira de Carlquist (1983, 1988), Wheeler \& Baas (1991) e outros, observaram fortes indícios da existência de relação entre pontoações guarnecidas, placas de perfuração simples e ambientes secos.

Ambas as espécies aqui analisadas apresentaram fibras libriformes e gelatinosas. Mimosa artemisiana, M. bimucronata, M. eriocarpa, M. incana, M. pilulifera e M. sparsa também apresentam estes tipos de fibras (Carnieletto \& Marchiori 1993; Marchiori 1993, 1996; Maccari \& Marchiori 1994; Paula 1995; Marchiori \& Muniz 1996). As fibras gelatinosas podem estar relacionadas ao lenho de tração quando ocorre tortuosidade no caule ou nos galhos ou terem a função de reserva de água, devido a grande quantidade em suas paredes da celulose que é hidrófila (Esau 1974; Paviani 1978), especialmente em ambientes com grandes períodos de seca como a caatinga. Leme et al. (2010), analisando o carvão destas duas espécies nos mesmos locais, Sertânia e Serra Talhada, evidenciaram também as fibras gelatinosas.

Quanto ao parênquima em faixas, Wheeler \& Baas (1991) afirmaram que é mais comum nas regiões tropicais do que nas temperadas. Alves \& Angyalossy-Alfonso (2000), analisando a flora arbórea de várias regiões brasileiras, comprovaram esta evidência. Esses resultados estão de acordo com as características de $M$. tenuiflora que apresenta grande quantidade de parênquima axial, conforme citado anteriormente. Zimmermann (1983) afirmou que, durante estações desfavoráveis, árvores decíduas baixam até zero a taxa de transpiração, sendo o fluxo de água condicionado à pressão osmótica. Para gerar esse fluxo é necessária a liberação constante de açúcares para manter elevada a pressão osmótica dentro dos vasos. Esse açúcar é disponibilizado pelo tecido parenquimático (Braun 1984).

Mimosa ophthalmocentra diferiu de M. tenuiflora e das espécies do gênero anteriormente citadas, pois apresenta parênquima axial escasso. Essa espécie apresenta outro tipo de adaptação para sobrevivência, como uma maior 
quantidade de células com paredes espessadas (esclerificadas). Arens (1958) observou que no cerrado as espécies têm dificuldade para realização da fotossíntese por conta da deficiência de minerais no solo. Assim, essas espécies tendem a apresentar um alto grau de esclerificação, que foi denominado escleromorfismo oligotrófico. Na caatinga, existem problemas como muita luminosidade, elevadas temperaturas e altos índices de evapotranspiração, dificultando a sobrevivência das plantas. Todavia, elas apresentam diferentes estratégias de sobrevivência, como a queda de folhas no período de estiagem. Outra estratégia ocorre no umbuzeiro (Spondias tuberosa Arruda, Anacardiaceae), que é a presença de parênquima aquífero nas suas raízes. Pela dificuldade de obtenção de água na caatinga, pode-se inferir então que $M$. ophthalmocentra utiliza também como estratégia de sobrevivência a esclerificação das células, resultando, portanto, em uma maior percentagem de fibras. Porém, estudos mais detalhados devem ser realizados para melhor esclarecimento dessa questão na caatinga, comparando-se espécies de locais em diferentes altitudes relacionando a estrutura da madeira com os fatores do meio.

Em Serra Talhada, a precipitação pluviométrica e a temperatura são mais elevadas, porém a altitude é menor em relação à Sertânia. Apesar da maior pluviosidade, a temperatura mais elevada leva a uma maior evapotranspiração. Considerando-se que a atividade cambial está relacionada com os fatores climáticos (Rao \& Rajput 1999; Salvador et al. 1997), pode-se observar que os espécimes estudados em Serra Talhada apresentam uma maior taxa de esclerificação representada pela maior percentagem de fibras no lenho, corroborando Webber (1936) e Baas (1982). Estes autores observaram que os diferentes componentes anatômicos da madeira resultantes da atividade do câmbio vascular podem apresentar diferenças quantitativas em função das adaptações ao ambiente e situação fisiológica do fluxo da água.

\section{Comparação quanto ao potencial energético das espécies}

Notou-se que Mimosa ophthalmocentra apresenta parênquima axial escasso, enquanto em $M$. tenuiflora o parênquima é vasicêntrico em faixas e em confluência. Além disso, o comprimento e o diâmetro dos elementos de vaso e dos raios são maiores em M. tenuiflora. Segundo Paula (1989), as madeiras com potencial energético, ou seja, as ricas em celulose e lignina são aquelas com alta frequência de fibras com paredes espessas, poucos vasos e de diâmetro grande, parênquima axial pouco ou ausente e raios baixos, densidade básica a partir de $0,60 \mathrm{~g} / \mathrm{cm}^{3}$. Assim, pode-se observar que M. ophthalmocentra, por possuir características semelhantes, porém parênquima axial escasso, apresenta potencial energético mais alto, em virtude de apresentar maior teor de celulose e lignina. Portanto, pode-se identificar outra diferença entre as duas espécies, sendo a madeira de $M$. ophthalmocentra potencialmente mais energética.
O lenho dos galhos das duas espécies estudadas apresenta potencial para produção de energia tanto em Sertânia quanto em Serra Talhada. Assim, reservando as proporções, pode-se utilizar os galhos, mantendo-se os troncos, evitando-se assim a extinção da espécie, além de facilitar o manuseio em caso de uso para lenha.

Mimosa ophthalmocentra e M. tenuiflora revelaram que, pela grande percentagem de fibras e pouca percentagem de vasos e raios, o lenho, desde a sua fase juvenil, que é o momento inicial do crescimento secundário, próximo da medula, apresenta potencial para produção de carvão e lenha. Resultados semelhantes foram obtidos nas análises dos galhos.

\section{Densidade}

Segundo Chimello (1980), a densidade da madeira é considerada a sua propriedade física mais importante, relacionando-se com outras propriedades e a sua utilização. Dessa forma, a madeira de maior densidade apresenta, em geral, uma maior resistência mecânica e alto valor energético. Isto porque a densidade está diretamente relacionada à quantidade de celulose que a constitui (Angyalossy et al. 2005). O lenho de Mimosa ophthalmocentra e M. tenuiflora apresenta alto valor de densidade, tanto no tronco como nos galhos, demonstrando alto valor energético, corroborando com o proposto por Oliveira et al (2006), que analisou a densidade e o rendimento gravimétrico em carvão e em carbono fixo em M. tenuiflora da Paraíba. Gasson (1987) e Rao et al. (1997) encontraram relação entre densidade da madeira e percentagem e diâmetro dos elementos de vaso. Eles observaram que a madeira com baixa frequência de vasos apresenta alta densidade. Fujiwara et al. (1991) observaram, em madeiras do Japão, que a espessura da parede das fibras e a percentagem de material da parede tem influência direta na densidade da madeira. Quanto mais alta for a massa específica (densidade) da madeira maior será o rendimento de energia em virtude do maior teor de celulose e lignina. Assim, pode-se afirmar que os componentes da madeira têm uma influência direta na qualidade da sua madeira para produção de energia. Portanto, as duas espécies aqui estudadas apresentam características anatômicas da madeira que as qualificam como espécies potencialmente energéticas.

A percentagem de fibras nas duas espécies apresenta valores acima de $35 \%$, o que determina a alta densidade de ambas. Mimosa tenuiflora, apesar de possuir alta percentagem de parênquima axial, apresenta baixa percentagem de vasos, enquanto $M$. ophthalmocentra apresenta baixa percentagem de parênquima axial e maior percentagem de vasos. Por esta razão, a densidade das duas espécies foi semelhante, tornando-as aptas para a produção de energia.

Pelas altas densidades do alburno e do cerne do tronco e dos galhos de M. ophthalmocentra e M. tenuiflora, pode-se afirmar, levando-se em consideração os parâmetros ana- 
tômicos aqui analisados radialmente (no sentido medula casca), que o lenho dessas espécies apresenta alto potencial energético. Portanto, pode ser utilizado para a produção de carvão, lenha e álcool combustível, inclusive como já foi citado anteriormente, desde a fase de lenho juvenil.

Concorda-se com Paula (1989) quando ressalta que madeira de boa qualidade para a produção de energia, especialmente carvão e lenha, só será viável do ponto de vista econômico e ecológico se as espécies estiverem incluídas na formação de grandes maciços florestais heterogêneos sob planos de manejo ecológico de rendimento sustentado, a fim de evitar o extrativismo em alta escala para fins energéticos. Portanto, M. ophthalmocentra e M. tenuiflora, "jurema-deimbira" e "jurema-preta" respectivamente, que apresentam potencial energético, devem ser incluídas em projetos de manejo sustentável na caatinga para estimular o seu uso de maneira racional, como um recurso renovável que é para populações atuais e as futuras gerações.

\section{Considerações finais}

A observação dos troncos de Mimosa ophthalmocentra e de $M$. tenuiflora demonstra distinção expressa através do tipo de casca e coloração do cerne e alburno, contribuindo assim para um melhor diagnóstico taxonômico dessas espécies.

Com base na anatomia da madeira aqui analisada, ambas as espécies apresentam características de lenho que podem contribuir na distinção das mesmas na caatinga pernambucana. M. ophthalmocentra apresentou camadas de crescimento constituídas por linhas de parênquima axial contendo cristais, parênquima axial escasso e menor percentagem de raios, enquanto a $M$. tenuiflora apresenta camadas de crescimento distintas, delimitadas por parênquima em linha, porém sem cristais, parênquima axial vasicêntrico, em faixas e em confluência e maior percentagem de raios.

M. ophthalmocentra e M. tenuiflora exibiram o lenho com as características anatômicas comuns às diversas espécies do gênero Mimosa. Todavia, a análise quali-quantitativa indicou que existem variações de algumas características entre as duas espécies que podem estar relacionadas à sua sobrevivência no ambiente caatinga, onde a vegetação está sujeita a alta incidência luminosa e ao déficit hídrico, como por exemplo a presença de fibras gelatinosas e fibras com paredes muito espessadas e pontuações guarnecidas.

Pelos parâmetros aqui analisados (percentagem de vasos, raios, parênquima e fibras e espessura de paredes das fibras) concluiu-se que $M$. ophthalmocentra e M. tenuiflora podem ser utilizadas para produção de álcool combustível e carvão. Todavia, M. ophthalmocentra por apresentar parênquima escasso e menor percentagem de raios, tem mais células de parede espessa e rica em celulose, consequentemente, maior potencial energético. Pela elevada densidade básica $\left(0,82-1,06 \mathrm{~g} / \mathrm{cm}^{3}\right)$ da madeira no tronco e nos galhos, concluiu-se que $M$. ophthalmocentra e $M$. tenuiflora da caatinga, apresentam grande quantidade de celulose e lignina, portanto têm potencial para produção de álcool combustível e carvão vegetal, consequentemente, maior potencial energético.

A partir da aplicação de teste estatístico, para correlação entre a distância e a percentagem de células na análise da variação radial da madeira das espécies em estudo, pode-se concluir que existem diferenças significativas da região próxima do centro da madeira para a periferia. Propõe-se, portanto, o uso das madeiras das espécies estudadas para a obtenção de enrgia, desde a fase do lenho juvenil, momento este em que, em ambas, ocorreram maiores percentagens de fibras e vasos com menor diâmetro. Em M. tenuiflora, nessa fase, ocorre percentagem de parênquima ainda menor.

O diagnóstico aqui apresentado para as duas espécies de Mimosa fornece subsídios para um plano de manejo sustentável e aproveitamento das mesmas, inclusive pelo potencial energético dos galhos. Reservando-se as devidas proporções, a utilização dos mesmos pode ser útil porque evita o sacrifício dos indivíduos adultos e facilita o manuseio.

\section{Agradecimentos}

Este trabalho faz parte de um Projeto interinstitutional proposto pela Associação Plantas do Nordeste (APNE), intitulado "Manejo sustentável da vegetação da caatinga com ênfase na produção de carvão para uso doméstico pelas comunidades do Nordeste do Brasil", envolvendo as seguintes instituições: Royal Botanic Gardens, Kew (RBG Kew); Centro Nordestino de Informações sobre Plantas (CNIP); Empresa Pernambucana de Pesquisa Agropecuária (IPA), Universidade Estadual de Feira de Santana (UEFS) e Universidade Federal da Bahia (UFBA), com financiamento do Conselho Nacional de Desenvolvimento Científico e Tecnológico (CNPq), da Comissão de Aperfeiçoamento de Pessoal de Nível Superior (CAPES), do Kew Latin America Research Fellowships Programme (KLARF) e da Clothworkers Guild. Os autores agradecem também a Frans Pareyn e toda a equipe da Associação Plantas do Nordeste (APNE) pelo apoio total nas coletas do material botânico em campo, Amélia Baracat, Simon Mayo e a equipe do RBG Kew.

\section{Referências bibliográficas}

Alves, S.P. de \& Angyalossy-Alfonso, V. 2000. Ecological trends in the wood anatomy of some Brazilian species. IAWA Journal 21(1): 3-20.

Angyalossy, V.; Amano, E. \& Alves, E. S. 2005. Madeiras utilizadas na fabricação de arcos para instrumentos de corda: aspectos anatômicos. Acta Botanica Brasilica 19(4): 819-834.

Arens, K. 1958. O cerrado como vegetação oligotrófica. Boletim da Faculdade de Filosofia, Ciências e Letras da Universidade de São Paulo, Botânica 15: 59-77.

Baas, P. \& Carlquist, S. 1985. A comparison of the ecological wood anatomy of the floras of southern California and Israel. IAWA Bulletin 6(4): 349-354. 
Baas, P. 1982. Systematics, phylogenetic and ecological wood anatomy history and perspectives. p. 23-58. In: Baas, P. (Ed.). New perspectives in wood anatomy. Leiden, The Hague Martinus Nijhoff Publishers.

Baas, P.; Werker, E. \& Fahn, A. 1983. Some ecological trends in vessel characters. IAWA Bulletin 4: 141-159.

Barneby, R.C. 1991. Sensitivae censitae. A description of the genus Mimosa L. (Mimosaceae) in the New World. Memoirs of the New York Botanical Garden 65: 1-835.

Barnes, R.D. 2004. The Acacia tree: a sustainable resource for Africa. Penzance, Rowes the printers.

Barreta-Kuipers, T. 1981. Wood anatomy of Leguminosae: its relevance to taxonomy. Pp. 677-705. In: Polhill, R.M. \& Raven, P.H. (Eds.). Advances in legumes systematics 1. Kew, Royal Botanic Gardens.

Braun, H.J. 1984. The significance of the accessory tissues of the hydrosystem for osmotic water shifting as the second principle of water ascent, with some thoughts concerning the evolution of trees. IAWA Bulletin 5(4): 275-294

Camargo-Ricalde, S.L. 2000. Descripción, distribución, anatomía, composición química y usos de Mimosa tenuiflora (Fabaceae-Mimosoideae) em México. Revista de Biología Tropical 48(4): 1-23.

Carlquist, S. \& Hoekman, D. A. 1985. Ecological wood anatomy of the woody southern California flora. IAWA Bulletin 6(4): 319-348.

Carlquist, S. 1983. Wood anatomy of Onagraceae: further species; root anatomy; significance of vestured pits and allied structures in dicotyledon wood. Annals of the Missouri Botanical Garden 69(4): 755-769.

Carlquist, S. 1988. Comparative wood anatomy: systematic ecological and evolutionary aspects of dicotyledonean wood. Berlin, Springer-Verlag.

Carnieletto, C. \& Marchiori, J.N.C. 1993. Anatomia da madeira de Mimosa eriocarpa Benth. Ciência Florestal 3(1): 67-75.

Chimelo, J. 1980. Anotações sobre anatomia e identificações de madeiras. São Paulo, IPT.

Costa, J.A.S.; Nunes, T.S.; Ferreira, A.P.L.; Stradmann, M.T.S. \& Queiroz, L.P. de. 2002. Leguminosas forrageiras da caatinga: espécies importantes para as comunidades rurais do sertão da Bahia. Feira de Santana, Universidade Estadual de Feira de Santana, SASOP.

Esau, K. 1974. Anatomia das plantas com sementes. São Paulo, Edgard Blücher.

Fahn, A. 1990. Plant anatomy. 4. ed. Oxford, Pergamon Press.

Fedalto, L.C.; Mendes, I. da C.A. \& Coradin, V.T.R. 1989. Madeiras da Amazônia. Descrição do lenho de 40 espécies ocorrentes na floresta nacional de Tapajós. Brasília, IBAMA.

Figueirôa, J.M.; Pareyn, F.G.C.; Drumond, M.; Araújo, E.L. 2005. Madeireiras. Pp. 101-1330. In: Sampaio, E.V.S.B.; Pareyn, F.G.C.; de Figueirôa J.M. \& Santos Jr. A.G. (Eds.) Espécies da flora nordestina de importância econômica potencial. Recife, Associação Plantas do Nordeste (APNE).

Franceschi, V.R. \& Horner Jr., H.T. 1980. Calcium oxalate crystals in plants. Bot. Rev. 46: 361-427.

Fujiwara, S.; Sameshima, K.; Kuroda, K. \& Takamura, N. 1991. Anatomy and properties of Japanese hardwoods I. Variation of fibre dimensions and tissue proportions and their relation to basic density. IAWA Bulletin 12: 419-424.

Gasson, P. 1987. Some implications of anatomical variations in the wood of pedunculate oak (Quercus robur L.) including comparisons with common beech (Fagus sylvatica L.). IAWA Bulletin 8: 149-166.

Gasson, P.; Trafford, C.; Mathews, B. 2003. Wood anatomy of Caesalpinioideae. Pp. 63-93. In: Klitgaard, B.B. \& Bruneau, A. (Eds.). Advances in Legumes Systematics. part 10. Kew, Royal Botancic Gardens.

Giulietti, A.M.; Harley, R.M.; Queiroz, L.P. de; Barbosa, M.R. de V.; Neta, A.L.B. \& Figueiredo, M.A. 2002. Espécies endêmicas da caatinga. Pp. 103-176. In: Sampaio, E.V.S.; Giulietti, A.M.; Virgínio, J. \& GamarraRojas, C.F.L. (Eds.). Vegetação e flora da caatinga. Recife, Associação Plantas do Nordeste.

Herendeen, P.S. 2000. Structural evolution in the Caesalpinioideae (Leguminosae). Pp. 45-64. In: Herendeen, P.S. \& Bruneau, A. (Eds.). Advances in Legume Systematics. part 9. Kew, Royal Botanic Gardens.

Herendeen, P.S., and R. B. Miller. 2000. Utility of wood anatomic characters in cladistic analysis. IAWA J. 21: 247-276

IAWA Committee. 1989. IAWA list of microscopic features for hardwood identification. IAWA Bulletin 10: 219-332.
Jansen, S.; Baas, P.; Gasson, P.; Lens, F. \& Smets, E. 2004. Variation in xylem structure from tropics to tundra: evidence from vestured pits. Proceedings of the National Academy of Sciences 101(23): 8833-8837.

Jansen, S.; Baas, P.; Gasson, P. \& Smets, E. 2003. Vestured pits: do they promote safer water transport? International Journal of Palnt Sciences 164(3): 405-413.

Johansen, D.A. 1940. Plant microtechnique. New York, McGraw -Hill Book Co.

Leme, C.L.D.; Cartwright, C. \& Gasson, P. 2010. Anatomical changes to the wood of Mimosa ophthalmocentra and Mimosa tenuiflora when charred at different temperatures. IAWA Journal 31(3): 333-351

Lewis, G.P. 2006. Leguminosae subfamília Mimosoideae. Pp. 86-90. In: Barbosa, M.R.V.; Sothers, C.; Mayo, S.; Gamarra-Rojas, C.F.L. \& Mesquita, A.C. Checklist das plantas do nordeste brasileiro: angiospermas e gymnospermas. Brasília, Ministério da Ciência e Tecnologia.

Lima, R.S.; Oliveira, P.L. \& Rodrigues, L.R. 2009. Anatomia do lenho de Enterolobium contortisiliquum (Vell.) Morong (LeguminosaeMimosoideae) ocorrente em dois ambientes. Revista Brasileira de Botanica 32(2): 361-374.

Lindorf, H. 1994. Eco-anatomical wood features of species from a very dry tropical Forest. IAWA Journal 15: 361-376.

Loureiro, A.A. \& Silva, M.F. 1968. Catálogo das madeiras da Amazônia. Belém, Ministério do Interior. Superintendência. Desenvolvimento da Amazônia (SUDAM).

Luckow, M. 2005. Tribo Mimosaceae. Pp. 163-183. In: Lewis, G.P.; Schrire, B.; Mackinder, B. \& Lock, M. (Eds.). Legumes of the world. Kew, Royal Botanic Gardens.

Maccari, A. \& Marchiori, J.N.C. 1994. Estudo anatômico do xilema secundário de Mimosa sparsa Benth. Ciência Florestal 4(1): 105-112.

Maia, G.N. 2004. Caatinga, árvores e arbustos e suas utilidades. São Paulo, Leitura \& Arte.

Marcati, C.R., Angyalossy-Alfonso, V. \& Benetati, L. 2001. Anatomia comparada do lenho de Copaifera langsdorffii Desf. (LeguminosaeCaesalpinoideae) de floresta e cerradão. Revista Brasileira de Botânica 24: 311-320

Marchiori, J.N.C. \& Muñiz, G.I.B. de. 1996. Anatomia do xilema secundário de Mimosa pilulifera Benth. Ciência Florestal 6(1): 65-75.

Marchiori, J.N.C. 1982. A estrutura do xilema secundário de Mimosa daleoides Benth. (Leguminosae -Mimosoideae). Ciência e Natura 4: 107-113.

Marchiori, J.N.C. 1993. Anatomia da madeira e casca do maricá, Mimosa bimucronata (DC.) O. Kuntze. Ciência Florestal 3(1): 48-67.

Marchiori, J.N.C. 1996. Anatomia do xilema secundário de Mimosa incana (Spreng.) Benth. Ciência Florestal 6(1): 53-63.

Nakata, P.A. 2003. Advances in our understanding of calcium oxalate crystal formation and function in plants. Plant Sci., Limerick 164: 901-9.

Oliveira, E.; Vital, B.R.; Pimenta, A.S.; Lucia, R.M.D.; Ladeira, A.M. \& Carneiro, A.C.O. 2006. Estrutura anatômica da madeira e qualidade do carvão de Mimosa tenuiflora (Willd.) Poir. Rev. Árvore 30(2): 311-318.

Paula, J.E. de. 1989. Estudo da estrutura da madeira de espécies nativas, visando o seu aproveitamento na produção de energia e papel. Ciência e Cultura 41(4): 344-353.

Paula, J.E. de. 1995. Anatomia e dendrometria de Mimosa artemisiana e Eucalyptus grandis. Pesquisa Agropecuária Brasileira 30(6): 745-757.

Paula, J.E.; Silva-Júnior, F.G. da \& Silva, A.P.P. 2000. Caracterização anatômica de madeiras nativas de matas ciliares do centro-oeste brasileiro. Scientia Forestalis 58: 73-89.

Paviani, T.I. 1978. Anatomia vegetal e cerrado. Ciência e Cultura 30 : 1076-1086.

PROBIO 2000. Seminário sobre avaliação e identificação de ações prioritárias para a conservação, utilização sustentável e repartição de benefícios da biodiversidade do bioma caatinga. Disponível em: http://www.biodiversitas.org/caatinga. (Acesso em 20/07/2001).

Queiroz, L.P. 2009. Leguminosas da caatinga. Feira de Santana, Universidade Estadual de Feira de Santana.

Rao, K.S. \& Rajput, K.S. 1999. Seasonal behavior of vascular cambium in teak (Tectona grandis) growing in moist deciduous and dry deciduous forests. IAWA Journal 20(1): 85-93. 
Rao, R.V.; Aebischer, D.P. \& Denne, M.P. 1997. Latewood density in relation to wood fibre diameter, wall thickness, and fibre and vessel percentages in Quercus robur. IAWA Journal 18: 127-138.

Ribeiro, M.L.R.C. \& Barros, C.F. 2006. Variação intraspecifica do lenho de Pseudopiptadenia contorta (DC.) G.P. Lewis \& M.P. Lima (Legumonosae Mimosoideae) de populações ocorrentes em remanescentes de Floresta Atlântica. Acta Botanica Brasilica 20:839-844.

Salvador, P.V.; Diez, P.C.; Rontome, C.P. \& Marti, G.M. 1997. Stem xylem features in three Quercus (Fagaceae) species along a climatic gradient in NE Spain. Trees 12: 90-96.

Sampaio, E.V.S.B. \& Salcedo, I.H. 1993. Effect of different fire severities on coppicing of caatinga vegetation in Serra Talhada, PE, Brazil. CorvallisOregon-USA, 1993. Biotropica 25(4): 452-460.

Schrire, B.D.; Lewis, G.P. \& Lavin, M. 2005. Biogeography of the Leguminosae. Pp. 21-54. In: Lewis, G.P.; Schrire, B.; Mackinder, B. \& Lock, M. (Eds.). Legumes of the World. Kew, Royal Botanic Gardens.
Silva, J.S. \& Sales, M.F. 2008. O gênero Mimosa (LeguminosaeMimosoideae) na microrregião do Vale do Ipanema, Pernambuco. Rodriguesia 59(3): 435-448.

Soffiatti, P. \& Angyalossy-Alfonso, V. 1999. Estudo anatômico comparativo do lenho e da casca de duas espécies de Eugenia L. (Myrtaceae). Revista Brasileira de Botânica 22: 275-284.

Vital, B.R. 1984. Métodos de determinação de densidade da madeira. Viçosa, UFV.

Webber, I.E. 1936. The woods of sclerophyllous and desert shrubs of California. American Journal of Botany 23: 181-188.

Wheeler, E.A. \& Baas, P.1991. A survey of the fossil record for dicotyledons wood and its significance for evolutionary and ecological wood anatomy. IAWA Bulletin 12(3): 275-332.

Wilkins, A.P. \& Papassotiriou, S. 1989. Wood anatomical variation of Acacia melanoxylon in relation to latitude. IAWA Bulletin 10:201-207.

Zimmermann, M.H. 1983. Xylem structure and the ascent of sap. Berlin, Springer Verlag. 